\title{
CARACTERIZAÇÃO ESPAÇO-TEMPORAL DOS COMPONENTES DO BALANÇO DE RADIAÇÃO E CALOR NA REGIÃO DE TRANSIÇÃO AMAZÔNIA-CERRADO
}

\author{
ARAUJO, Mayara Lucyanne Santos de - mayara.araujo.eng@gmail.com \\ Universidade de Brasília / UNB
}

SANTOS, Jessflan Rafael Nascimento - jessflanrns@gmail.com Universidade Ceuma / UNICEUMA

FEITOSA, Francisco Emenson Carpegiane Silva emersoncarpegiane123@gmail.com Universidade Ceuma / UNICEUMA

\section{SANTOS, Juliana Sales dos - julianasales.engenharia@gmail.com Universidade Ceuma / UNICEUMA}

\author{
SILVA, Vilena Aparecida Ribeiro - vilenaribeirosilva@gmail.com \\ Instituto Federal do Maranhão / IFMA \\ ALMEIDA, Juliana Lopes - july01.jl@gmail.com \\ Universidade Ceuma / UNICEUMA
}
RIBEIRO, Camila Viegas - camila.viegas022@hotmail.com Universidade Ceuma / UNICEUMA

\author{
SILVA, Fabrício Brito - fabrícioagro@gmail.com \\ Universidade Ceuma / UNICEUMA
}

\begin{abstract}
RESUMO: Os processos radiativos na superfície são de crucial importância para redistribuição de umidade e de calor no solo e na atmosfera, pois as trocas de calor e umidade afetam o comportamento da biosfera, do tempo e do clima na Terra. Os estudos de modelagem climática utilizam como parâmetros os componentes do balanço de radiação e calor na superfície, com as trocas de energia na interface vegetaçãoatmosfera. O objetivo do presente trabalho foi caracterizar espaço-temporalmente os componentes do balanço de radiação e calor no Maranhão, por meio de dados provenientes da base Global Land Data Assimilation System - GLDAS, no período de 2000 a 2014. Foram realizadas técnicas de estatística descritiva, como a medida de tendência central e de variabilidade de dados para caracterização dos mesmos. As médias mensais da radiação de ondas curtas incidente e do saldo de radiação de ondas curtas, no bioma Amazônico, não evidenciaram um comportamento diferenciado entre os períodos seco e chuvoso. Por sua vez, a radiação de ondas curtas incidente e o saldo de radiação de ondas curtas, no bioma Cerrado, apresentaram médias mensais superiores no período seco. O fluxo de calor sensível e o fluxo de calor no solo, nos biomas Cerrado e Amazônia, também apresentaram médias mensais superiores no período seco. A radiação de ondas longas incidente, o saldo de radiação de ondas longas e o fluxo de calor latente, nos biomas Cerrado e Amazônia, apresentaram médias mensais superiores no período chuvoso. De maneira geral, a base de dados GLDAS viabiliza os estudos de planejamento ambiental em regiões de escassez de dados climáticos, como o estado do Maranhão.
\end{abstract}

PALAVRAS-CHAVES: mudanças climáticas, sensoriamento remoto, modelagem climática. 
ABSTRACT: Radiative surface processes are of crucial importance for the redistribution of moisture and heat in the soil and in the atmosphere as heat and humidity changes affect the behavior of the biosphere, weather and climate on Earth. The climatic modeling studies use as components the components of the radiation and heat balance in the surface, with the energy exchanges at the vegetation-atmosphere interface. The objective of the present work was to characterize space-time components of the radiation and heat balance in Maranhão, using data from the Global Land Data Assimilation System (GLDAS) database, from 2000 to 2014. Descriptive statistics techniques, as the measure of central tendency and variability of data to characterize them. The monthly mean of incident shortwave radiation and the short wave radiation balance in the Amazon biome did not show a differentiated behavior between dry and rainy periods. In turn, the incident short-wave radiation and the shortwave radiation balance in the Savanna biome showed higher monthly averages in the dry period. Sensitive heat flux and soil heat flux, in the Savanna and Amazon biomes, also presented higher monthly means in the dry period. The incident long-wave radiation, the long-wave radiation balance and the latent heat flux in the Savanna and Amazon biomes, presented higher monthly averages in the rainy season. In general, the GLDAS database facilitates environmental planning studies in zones of climate data scarcity, such as the state of Maranhão.

KEYWORDS: Climate change, remote sensing, climate modeling.

\section{INTRODUÇÃO}

Os estudos climáticos que compreendem a radiação solar e terrestre são de crucial importância, devido esta ser a fonte de energia determinante para os processos biológicos e físicos na atmosfera (LEITÃO, 1994). É a fonte primária de todos os fenômenos atmosféricos e de processos físicos, químicos e biológicos observados em ecossistemas. A radiação solar é responsável direta na disposição da energia para os processos solo-planta-atmosfera (QUERINO et al., 2006), e pode ser aproveitada sob várias formas, tais como a captura pela biomassa, o aquecimento do ar e da água para fins diversos, fotoeletricidade, etc. (PEREIRA et al., 2002).

A energia solar determina a disponibilidade da produtividade das culturas agrícolas (COCKSHULL et al., 1992), pois a vegetação é um importante receptor e armazenador da radiação solar (JARVIS et al., 1997). O conhecimento dos componentes do balanço de energia fundamenta o planejamento agrícola em relação à estimativa das perdas de água por evapotranspiração e caracterização do micro clima local (BORGES et al., 2008; PEREIRA, 2002).

A redistribuição e trocas de calor no solo e na atmosfera afetam diretamente o comportamento da biosfera, do tempo e do clima na Terra (BASTIAANSSEN, 1998; ROERINK et al., 2000). As mudanças no balanço de radiação no sistema terra oceano-atmosfera, principalmente nos trópicos, influem no clima global (AGUTTES et al., 2000), e geram significativas alterações à sobrevivência dos ecossistemas, com vários efeitos potenciais sobre indivíduos, populações e comunidades (WALTHER et al., 2002).

Os componentes do balanço de radiação e calor na superfície possuem grande importância para a calibração de modelos climáticos e hidrológicos, sendo essenciais para modelagem climática (BALDOCCHI E MEYERS, 1998). As tentativas de identificação da variabilidade climática são de suma importância para os estudos socioeconômicos, uma vez que podem apresentar tendências, ou seja, visualizar cenários futuros para uma melhor compreensão da dinâmica 
climática (QUEIROZ et al., 2012), prevendo como futuras variações podem afetar o ambiente.

Os dados provenientes de modelos globais e sensoriamento remoto possuem grande relevância nacional, uma vez que o Brasil possui grande escassez de dados climáticos. Desse modo, essas fontes constituem uma alternativa para quantificar os fluxos de energia e calor entre a atmosfera e a superfície terrestre, com o fornecimento quase contínuo de dados com alta resolução temporal (PAIVA, 2005). Possibilitando a geração de subsídios em planejamento ambiental e energético em localidades de difícil acesso e de alto custo.

O estado do Maranhão possui uma grande diversidade ambiental e socioeconômica, estando situado em uma região geográfica estratégica (zona de transição Amazônia-Cerrado) por abranger diversos tipos de ecossistemas e acolher uma vasta biodiversidade. Possui os climas semiárido do interior do Nordeste e úmido equatorial da Amazônia, que refletem nas formações vegetais que transicionam da Savana (Cerrado) no Sul para as florestas estacionais no Centro e na parte Leste, assim como, para a floresta ombrófila no Noroeste do estado (MONTES, 1997). Apesar dessa relevância ambiental, dados e estudos climáticos no estado são escassos.

O presente trabalho teve por objetivo caracterizar espaço-temporalmente os componentes do balanço de radiação e calor na região de transição Amazônia-Cerrado, por meio do modelo climático global GLDAS (Global Land Data Assimilation System).

\section{MATERIAL E MÉTODOS}

\section{1 ÁREA DE ESTUDO}

O estado do Maranhão está localizado no Extremo Ocidental do Nordeste brasileiro e Extremo Leste da Bacia Amazônica, entre os paralelos $1^{\circ} 01^{\prime} \mathrm{e}$ $10^{\circ} 21^{\prime}$ Sul e os meridianos 41 $48^{\prime}$ e $48^{\circ} 50^{\prime}$ Oeste (Figura 1). Abrange uma área superficial de $331.936,955 \mathrm{~km}^{2}$ (IBGE, 2015), sendo o oitavo maior estado brasileiro e o segundo do Nordeste em extensão territorial. Sua população é de 6.574.789 habitantes, com uma densidade populacional de $19,81 \mathrm{hab} . / \mathrm{km}^{2}$ (IBGE, 2010). O estado encontra-se localizado entre três macrorregiões brasileiras: Nordeste, Norte e Centro-Oeste. 


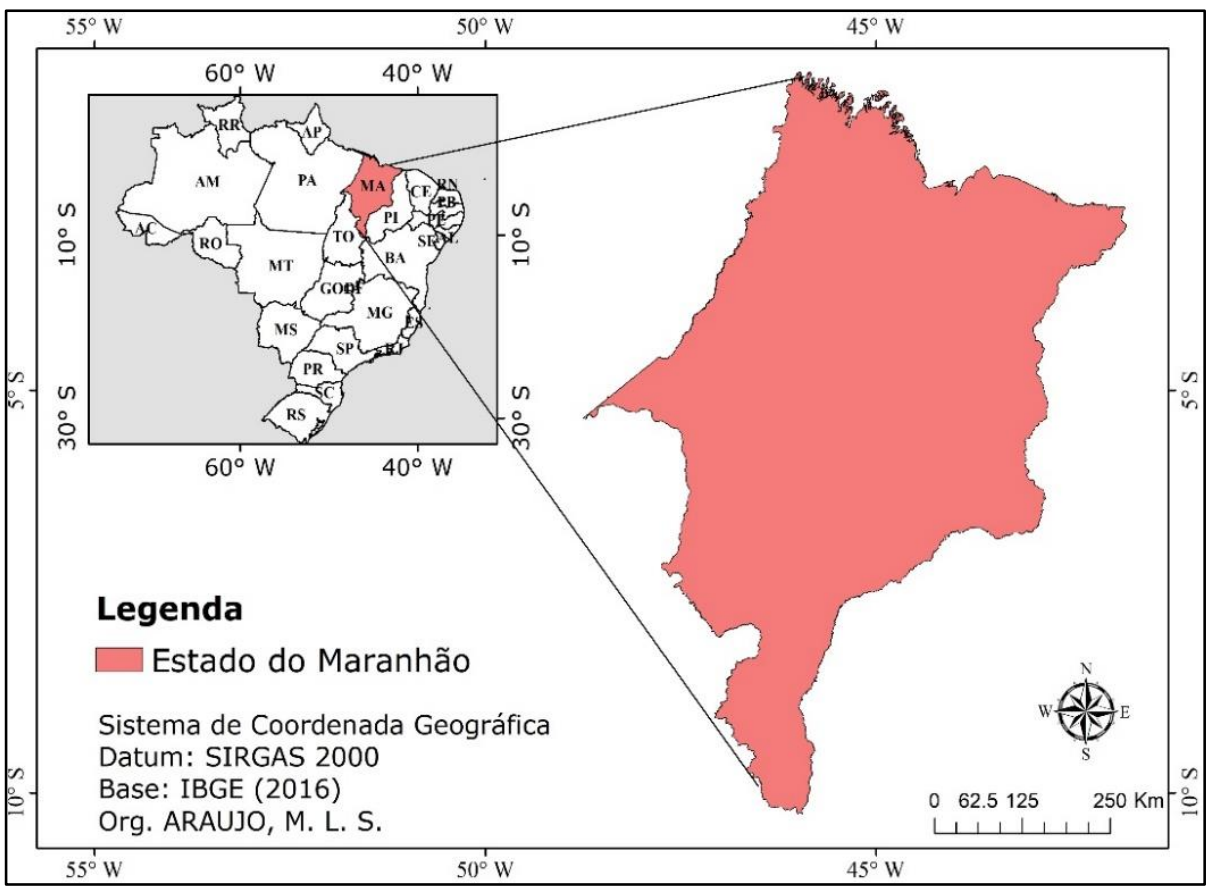

Figura 1 - Localização do estado do Maranhão, área de estudo do presente trabalho.

Localizado em uma zona de transição entre o bioma Cerrado e Amazônia, dispõe de grande variabilidade climática e fitofisionômica. Fisiograficamente o Maranhão apresenta sete microrregiões: Litoral, Baixada Maranhense, Cerrados, Cocais, Amazônia, Chapadões e Planalto (MARANHÃO, 2002). Apresenta dois tipos de clima em sua área geográfica: a Noroeste domina o clima tropical quente e úmido, típico da região Amazônica, no Sudeste é marcado o clima tropical quente e semiúmido.

A vegetação reflete os aspectos transacionais do clima e das condições edáficas da região de transição entre a Amazônia (úmida) e a Savana (semiárida). Dessa forma, resultaram variados ecossistemas, desde ambientes salinos com presença de manguezais, passando por campos inundáveis, cerrados e babaçuais, até vegetação florestal de grande porte com características da Amazônia (MUNIZ, 2006).

\subsection{CARACTERIZAÇÃO E ANÁLISE DOS DADOS}

Os dados climatológicos de ondas curtas incidente, saldo de radiação de ondas curtas, ondas longas incidente, saldo de radiação de ondas longas, fluxo de calor latente, fluxo de calor sensível e fluxo de calor no solo foram adquiridos a partir da base Global Land Data Assimilation System (GLDAS), fornecidos gratuitamente no site da NASA (National Aeronautics and Space Administration). Foram utilizados registros mensais do período de 2000 a 2014.

O GLDAS é um projeto desenvolvido com o objetivo de produzir uma nova geração de dados climáticos espaciais e medidos na superfície (SILVA, 2013). Consiste em um modelo global que fornece uma reanálise dos dados provenientes de estações meteorológicas distribuídos em todo o planeta e dados 
de satélites orbitais meteorológicos (RODELL et al., 2004). Possui uma base de dados de alta resolução temporal, com várias variáveis para o balanço da água, de energia e parâmetros forçados (AWANGE et al., 2014).

Os dados GLDAS foram obtidos no mesmo ponto geográfico das estações meteorológicas em virtude da possibilidade de uma referência climatológica da região (Figura 2). Assim, foi possível a caracterização dos períodos seco e chuvoso, e dos biomas Amazônico e Cerrado. No bioma Amazônico foram obtidos dados referentes aos municípios de Bacabal, São Luís, Turiaçu e Zé Doca. No bioma Cerrado foram obtidos dados de Alto Parnaíba, Balsas, Barra do Corda, Carolina, Caxias, Chapadinha, Colinas e Imperatriz.

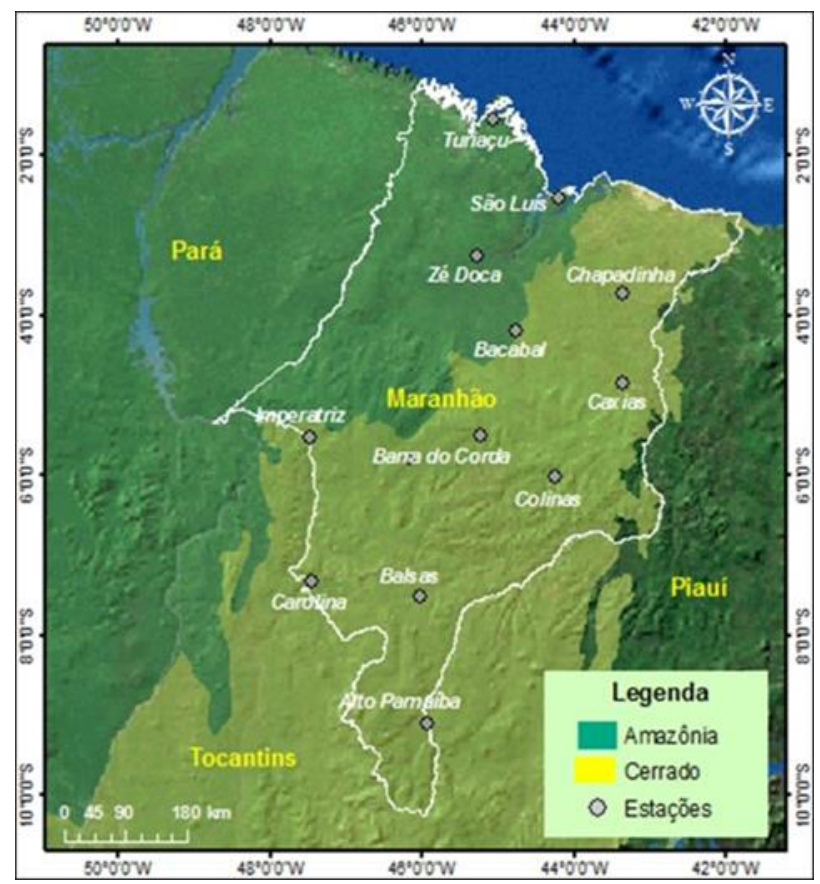

Figura 2 - Localização das 12 estações meteorológicas no estado do Maranhão (INMET) destacando os biomas Amazônico e Cerrado.

Posteriormente foram caracterizados e analisados estatisticamente, com análises de média mensal, média mensal máxima, média mensal mínima, desvio padrão e coeficiente de variação.

\section{RESULTADOS E DISCUSSÃO}

Os dados referentes as ondas curtas incidente, saldo de radiação de ondas curtas, ondas longas incidente, saldo de radiação de ondas longas, calor latente, calor sensível e fluxo de calor no solo foram caracterizados nas estações seca e chuvosa para o período de 2000 a 2014, nos biomas Amazônico e Cerrado, no Maranhão.

De maneira geral, as estações presentes no bioma Amazônico indicaram a ocorrência da estação seca entre julho a novembro e a estação chuvosa entre dezembro a junho. No bioma Cerrado, de maneira geral, a estação seca ocorreu 
entre maio a novembro e a estação chuvosa entre dezembro a abril (SILVA et al., 2016).

\subsection{RADIAÇÃO DE ONDAS CURTAS INCIDENTE}

No bioma Amazônico os valores de radiação de ondas curtas incidente não apresentaram grande variabilidade entre as localidades, bem como nos períodos seco e chuvoso, apresentando o coeficiente de variação entre $29 \%$ a $36 \%$ (Figura 2). O valor máximo foi observado em São Luís $\left(248 \mathrm{~W} / \mathrm{m}^{2}\right.$ em setembro) e o valor mínimo em Zé Doca (187 W/m² em janeiro).
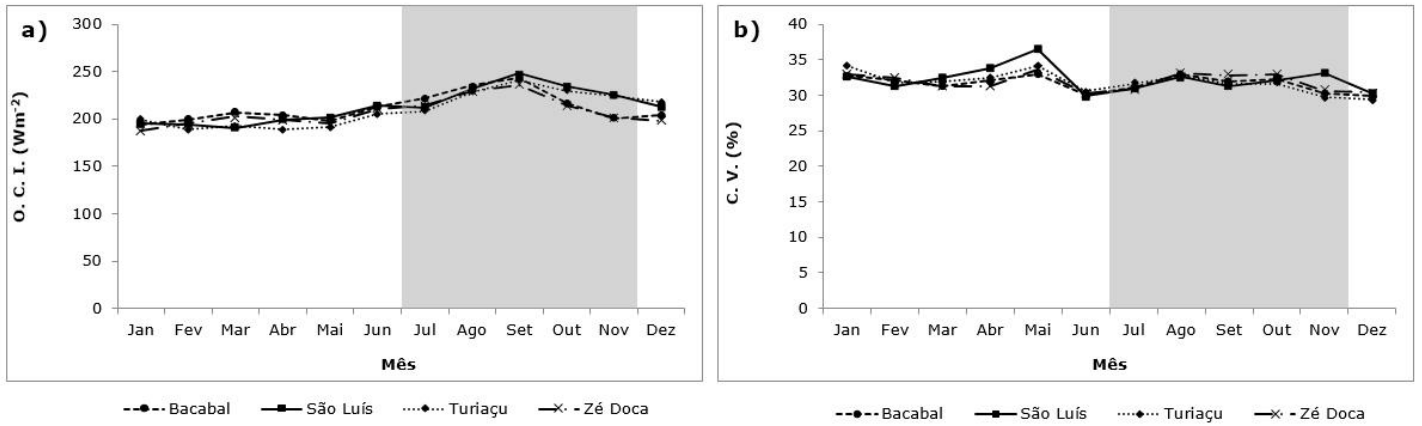

Figura 3 - a) Média mensal do período de 2000 a 2014 de ondas curtas incidente (O. C. I.) nas localidades do bioma Amazônico no estado do Maranhão. b) Coeficiente de variação (C. V.) mensal de ondas curtas incidente nas localidades do bioma Amazônico no estado do Maranhão. A região sombreada corresponde ao período seco.

Andrade et al. (2009) verificaram valores semelhantes na Reserva Biológica do Jaru (Rondônia), com o pico de radiação de ondas curtas incidente mensais no período chuvoso de $182 \mathrm{~W} / \mathrm{m}^{2}$ e no período seco de $211 \mathrm{~W} / \mathrm{m}^{2}$. Assim como Souza et al. (2002) e Culf et al. (1996) verificaram o mesmo comportamento em outras localidades do bioma Amazônico. Rocha et al. (2004) consideram a nebulosidade um fator significante para a diminuição da intensidade de radiação incidente na superfície, o que explica a maior incidência de ondas curtas no período seco.

No bioma Cerrado as localidades apresentaram valores superiores no período seco e inferiores no período chuvoso (Figura $3 a$ ). Os maiores valores foram observados em Caxias e Chapadinha $\left(263 \mathrm{~W} / \mathrm{m}^{2}\right.$ e $260 \mathrm{~W} / \mathrm{m}^{2}$ em setembro, respectivamente). Os menores valores foram observados em Colinas e Imperatriz ( $188 \mathrm{~W} / \mathrm{m}^{2}$ em janeiro, em ambas localidades). O coeficiente de variação da radiação de ondas curtas incidente no bioma Cerrado apresentou valores que variou de 29 a 33 (Figura 3b). 

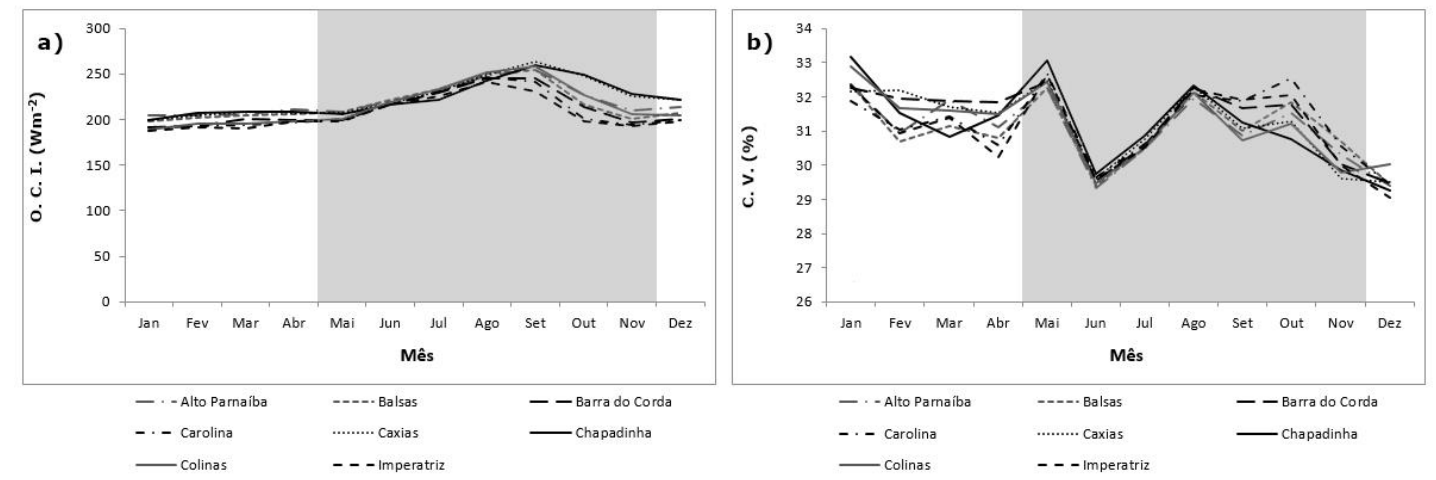

Figura 4 - a) Média mensal do período de 2000 a 2014 de ondas curtas incidente (O. C. I.) nas localidades do bioma Cerrado no estado do Maranhão. b) Coeficiente de variação (C. V.) mensal de ondas curtas incidente nas localidades do bioma Cerrado no estado do Maranhão. A região sombreada corresponde ao período seco.

Andrade et al. (2009), na Fazenda Maracaí (Mato Grosso), também localizado em uma área de transição Amazônia-Cerrado, verificaram maiores valores no período chuvoso comparado ao período seco, com $161 \mathrm{~W} / \mathrm{m}^{2}$ e 140 $\mathrm{W} / \mathrm{m}^{2}$, respectivamente. No período chuvoso, esse comportamento pode ser explicado pela variação anual do ângulo de incidência da radiação solar (VOURLITIS et al., 2008). No período seco, a maior incidência de queimadas pode atenuar em até 70\% da radiação incidente (ARTAXO et al., 2005).

\subsection{SALDO DE RADIAÇÃO DE ONDAS CURTAS}

No bioma Amazônico os valores do saldo de radiação de ondas curtas demonstraram um comportamento semelhante entre as localidades, bem como nos períodos seco e chuvoso (Figura 4a). O valor máximo foi observado em São Luís (215 W/m² em setembro) e o valor mínimo em Bacabal $\left(159 \mathrm{~W} / \mathrm{m}^{2}\right.$ em novembro). A média mensal de novembro em São Luís apresentou um pico em relação às demais localidades $\left(199 \mathrm{~W} / \mathrm{m}^{2}\right)$. O coeficiente de variação do saldo de radiação de ondas curtas apresentou valores entre 30\% a 56\% (Figura $4 \mathrm{~b}$ ). Os valores máximos foram observados em Bacabal, Turiaçu e Zé Doca no final do período seco ( $54 \%$, $56 \%$ e $54 \%$, respectivamente). 

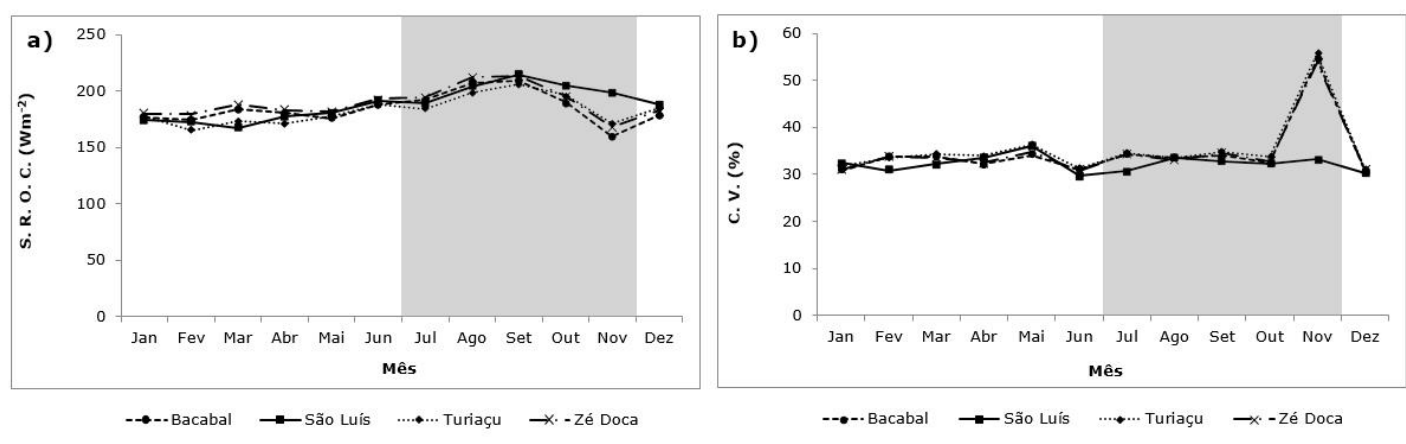

Figura 5 - a) Média mensal do período de 2000 a 2014 do saldo de radiação de ondas curtas (S. R. O. C.) nas localidades do bioma Amazônico no estado do Maranhão. b) Coeficiente de variação (C. V.) mensal do saldo de radiação de ondas curtas nas localidades do bioma Amazônico no estado do Maranhão. A região sombreada corresponde ao período seco.

Christoffersen et al. (2014), no bioma Amazônico e na transição Amazônia-Cerrado, verificaram maiores valores no período seco e menores no período chuvoso. O mesmo comportamento foi observado por Hasler e Avissar (2007) na Fazenda Nossa Senhora (Rondônia), por Andrade et al. (2009) na Reserva Biológica do Jaru (Rebio Jaru) e por Rocha et al. (2004) na Floresta Nacional de Tapajós.

No bioma Cerrado as localidades apresentaram valores superiores no período seco e inferiores no período chuvoso (Figura 5a). Chapadinha apresentou os maiores valores em toda a série temporal, com variação entre $184 \mathrm{~W} / \mathrm{m}^{2}$ (novembro) a $231 \mathrm{~W} / \mathrm{m}^{2}$ (setembro). O menor valor do saldo de radiação de ondas curtas foi observado em imperatriz $\left(154 \mathrm{w} / \mathrm{m}^{2}\right.$ em novembro). O coeficiente de variação apresentou valores entre 30 e 56, sendo os maiores valores no início do período chuvoso (Figura 5b).
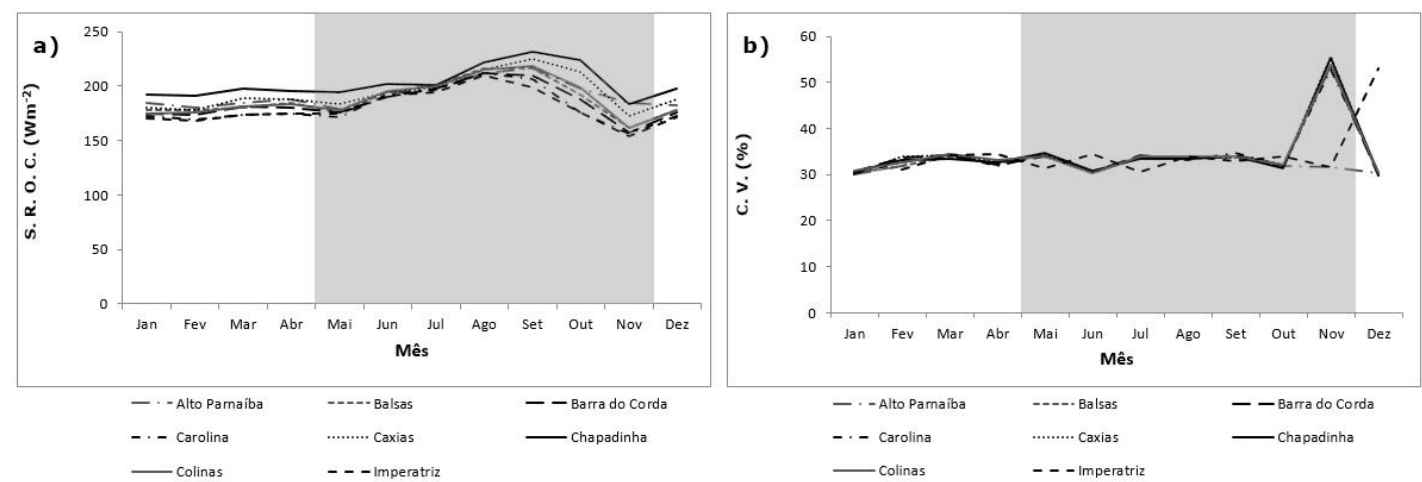

Figura 6 - a) Média mensal do período de 2000 a 2014 do saldo de radiação de ondas curtas (S. R. O. C.) nas localidades do bioma Cerrado no estado do Maranhão. b) Coeficiente de variação (C. V.) mensal do saldo de radiação de ondas curtas nas localidades do bioma Cerrado no estado do Maranhão. A região sombreada corresponde ao período seco. 
Em acordo com os dados encontrados neste trabalho, Christoffersen et al. (2014) verificaram maiores valores no período seco e menores no período chuvoso.

Andrade et al. (2009), na Fazenda Maracaí (Mato Grosso), pertencente a transição Amazônia-Cerrado, verificaram maiores valores no período chuvoso e menores no período seco, com $152 \mathrm{~W} / \mathrm{m}^{2}$ e $121 \mathrm{~W} / \mathrm{m}^{2}$, respectivamente. Giambelluca et al. (2009), na Reserva Ecológica do IBGE (Brasília), também no bioma Cerrado, verificaram valores de $220 \mathrm{~W} / \mathrm{m}^{2}$ (dezembro) no período chuvoso e $125 \mathrm{~W} / \mathrm{m}^{2}$ (junho) no período seco.

\subsection{RADIAÇÃO DE ONDAS LONGAS INCIDENTE}

No bioma Amazônico a radiação de ondas longas incidente apresentou valores superiores no período chuvoso e inferiores no período seco (Figura 6a). O valor máximo foi observado em São Luís (391 W/m² em março) e o valor mínimo em Bacabal (348 W/m² em julho). São Luís apresentou os maiores valores em praticamente toda série temporal, com pico de $391 \mathrm{~W} / \mathrm{m}^{2}$ em março e vale de $363 \mathrm{~W} / \mathrm{m}^{2}$ em setembro. O coeficiente de variação da radiação de ondas longas incidente apresentou valores entre $28 \%$ e $29 \%$ (Figura 6b).
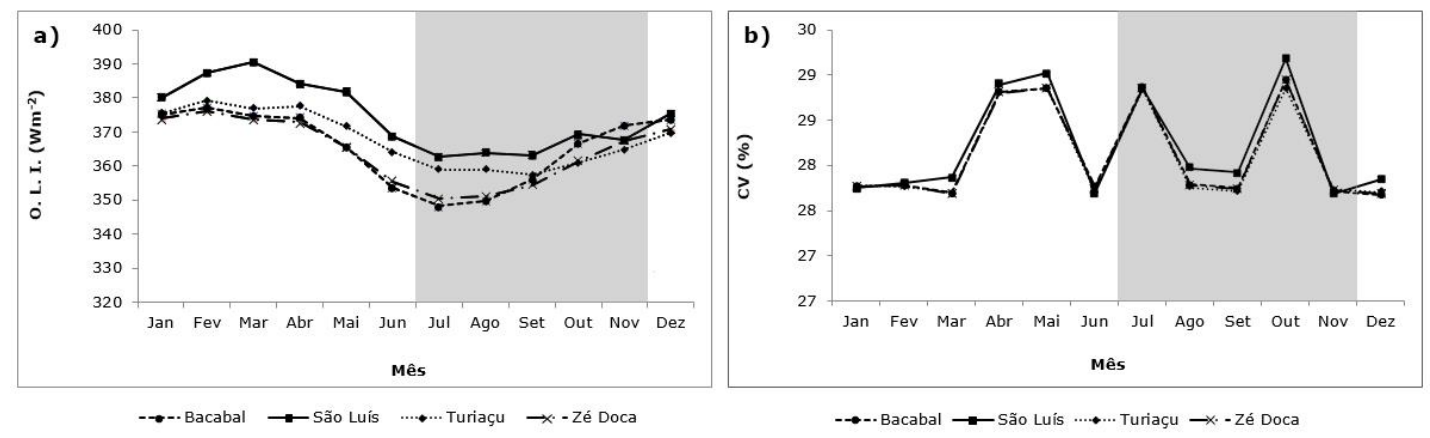

Figura 7 - a) Média mensal do período de 2000 a 2014 de ondas longas incidente (O. L. I.) nas localidades do bioma Amazônico no estado do Maranhão. b) Coeficiente de variação (C. V.) mensal do período de 2000 a 2014 de ondas longas incidente nas localidades do bioma Amazônico no estado do Maranhão. A região sombreada corresponde ao período seco.

Souza Filho et al. (2006), na Floresta Nacional de Caxiuanã (MelgaçoPA), também localizado no bioma Amazônico, verificaram maiores valores no período chuvoso e menores no período seco, com variações no período chuvoso de $339 \mathrm{~W} / \mathrm{m}^{2}$ a $417 \mathrm{~W} / \mathrm{m}^{2}$.

No bioma Cerrado os valores mensais não evidenciaram um comportamento diferenciado entre as localidades, com valores superiores no período chuvoso e inferiores no período seco, apresentando o coeficiente de variação entre $28 \%$ a $29 \%$ (Figura 7 ). O valor máximo foi observado em Imperatriz (378 W/m² em fevereiro) e o valor mínimo em Alto Parnaíba (325 $\mathrm{W} / \mathrm{m}^{2}$ em julho). 

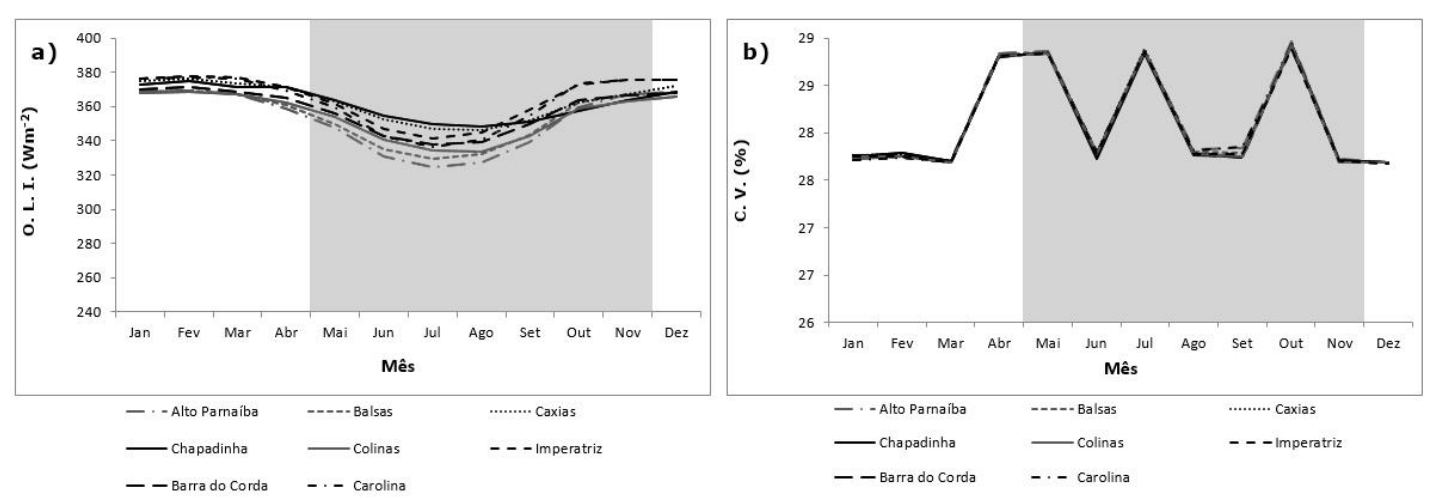

Figura 8 - a) Média mensal do período de 2000 a 2014 de ondas longas incidente (O. L. I.) nas localidades do bioma Cerrado no estado do Maranhão. b) Coeficiente de variação (C. V.) mensal do período de 2000 a 2014 de ondas longas incidente nas localidades do bioma Cerrado no estado do Maranhão. A região sombreada corresponde ao período seco.

\subsection{SALDO DE RADIAÇÃO DE ONDAS LONGAS}

No bioma Amazônico os valores do saldo de radiação de ondas longas revelaram um comportamento semelhante entre as localidades, com valores maiores no período chuvoso e menores no período seco, variando de $-29 \%$ a $44 \%$ (Figura 8). O valor máximo foi observado em São Luís (-44 W/m² em fevereiro/março) e o valor mínimo em Turiaçu $\left(-81 \mathrm{~W} / \mathrm{m}^{2}\right.$ em setembro).
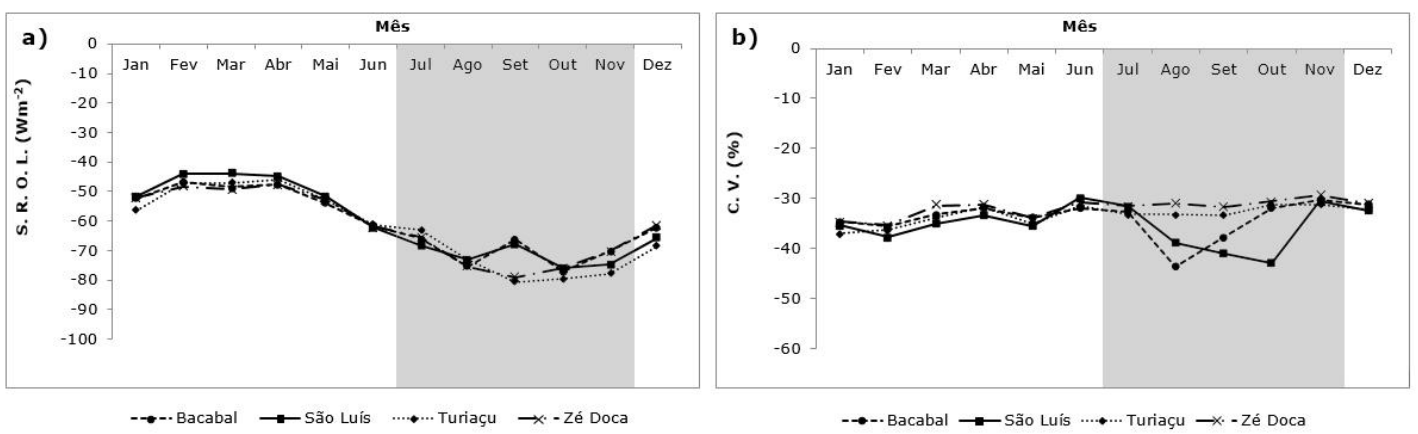

Figura 9 - a) Média mensal do período de 2000 a 2014 do saldo de radiação de ondas longas (S. R. O. L.) nas localidades do bioma Amazônico no estado do Maranhão. b) Coeficiente de variação (C. V.) mensal do período de 2000 a 2014 do saldo de radiação de ondas longas nas localidades do bioma Amazônico no estado do Maranhão. A região sombreada corresponde ao período seco.

No bioma Cerrado as localidades mostraram valores superiores no período chuvoso e inferiores no período seco (Figura 9a). O pico no período chuvoso foi observado em Imperatriz $\left(-44 \mathrm{~W} / \mathrm{m}^{2}\right.$ em fevereiro) e o vale no período seco em Balsas $\left(-101 \mathrm{~W} / \mathrm{m}^{2}\right.$ em agosto/setembro). O coeficiente de variação do saldo mensal de radiação de ondas longas no bioma Cerrado apresentou valores entre $-30 \%$ e $-36 \%$ (Figura 9b). 

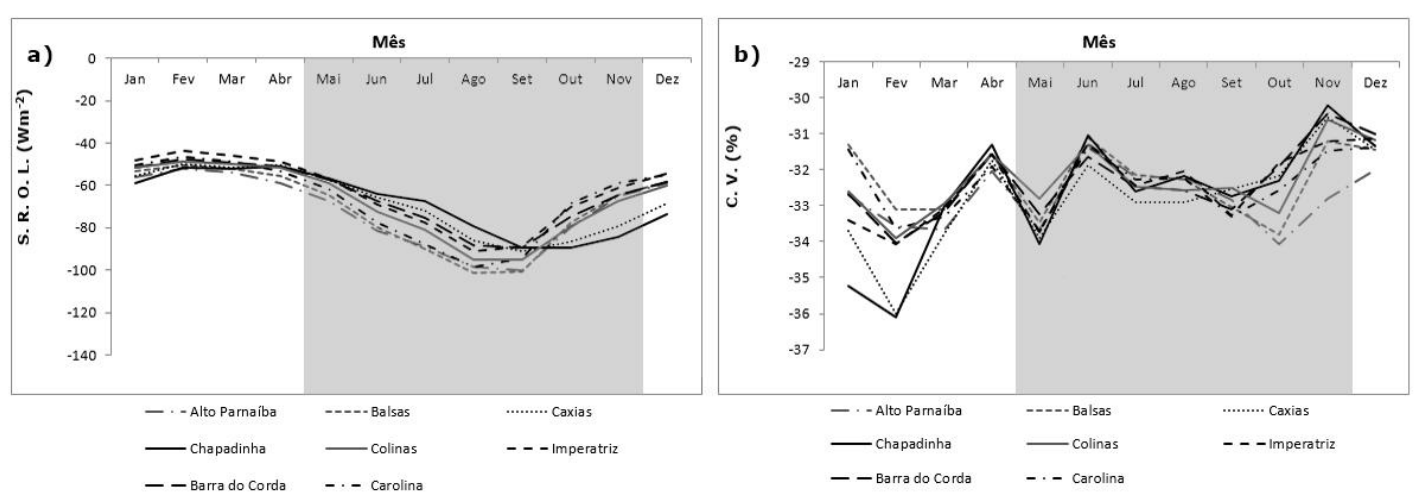

Figura 10 - a) Média mensal do período de 2000 a 2014 do saldo de radiação de ondas longas (S. R. O. L.) nas localidades do bioma Cerrado no estado do Maranhão. b) Coeficiente de variação (C. V.) mensal do período de 2000 a 2014 do saldo de radiação de ondas longas nas localidades do bioma Cerrado no estado do Maranhão. A região sombreada corresponde ao período seco.

\subsection{CALOR LATENTE}

No bioma Amazônico os valores do fluxo de calor latente foram maiores no período chuvoso e menores no período seco (Figura 10a). O valor máximo foi observado em Bacabal ( $116 \mathrm{~W} / \mathrm{m}^{2}$ em julho) e o valor mínimo em São Luís (25 $\mathrm{W} / \mathrm{m}^{2}$ em outubro). Bacabal e Zé Doca apresentaram uma semelhança sazonal, por exemplo, $116 \mathrm{~W} / \mathrm{m}^{2}$ e $115 \mathrm{~W} / \mathrm{m}^{2}$, respectivamente, no início do período seco (julho). O coeficiente de variação do fluxo de calor latente apresentou valores entre $29 \%$ e $105 \%$ (Figura $10 \mathrm{~b}$ ), com os maiores valores nas localidades de São Luís e Turiaçu no período seco.
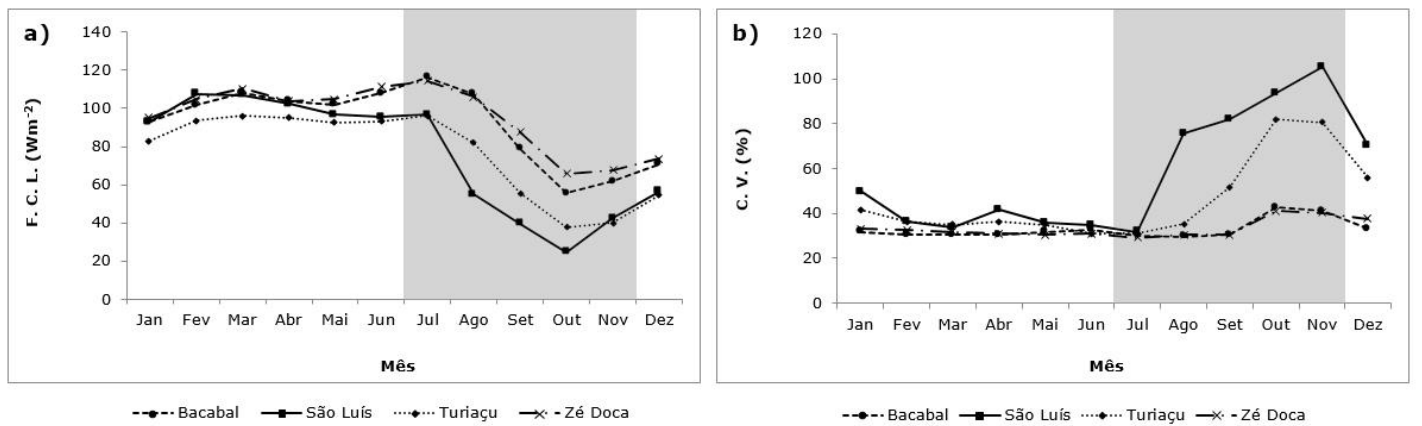

Figura 11 - a) Média mensal do período de 2000 a 2014 do fluxo de calor latente (F. C. L.) nas localidades do bioma Amazônico no estado do Maranhão. b) Coeficiente de variação (C. V.) mensal do período de 2000 a 2014 do fluxo de calor latente nas localidades do bioma Amazônico no estado do Maranhão. A região sombreada corresponde ao período seco.

No presente trabalho ficou evidenciado uma maior variação entre o período seco e chuvoso. Esse mesmo comportamento foi observado por Christoffersen et al. (2014) para a floresta de transição Amazônia-Cerrado e por 
Hasler e Avissar (2007), na Fazenda São Nicolau localizada no Mato Grosso (transição Amazônia-Cerrado).

Andrade et al. (2009), na Reserva Biológica do Jaru (Rebio Jaru), bioma Amazônico, não evidenciaram um comportamento diferenciado entre os períodos seco e chuvoso, com valores de $75 \mathrm{~W} / \mathrm{m}^{2}$ e $76 \mathrm{~W} / \mathrm{m}^{2}$, respectivamente.

No bioma Cerrado os valores mensais evidenciaram um comportamento diferenciado entre as localidades, com valores superiores no período chuvoso e inferiores no período seco, apresentando o coeficiente de variação entre $29 \%$ (período seco) e 62\% (período chuvoso) (Figura 11). O maior valor foi observado em Imperatriz (115 W/m² em junho) e o menor valor em Alto Parnaíba ( $41 \mathrm{~W} / \mathrm{m}^{2}$ em setembro).
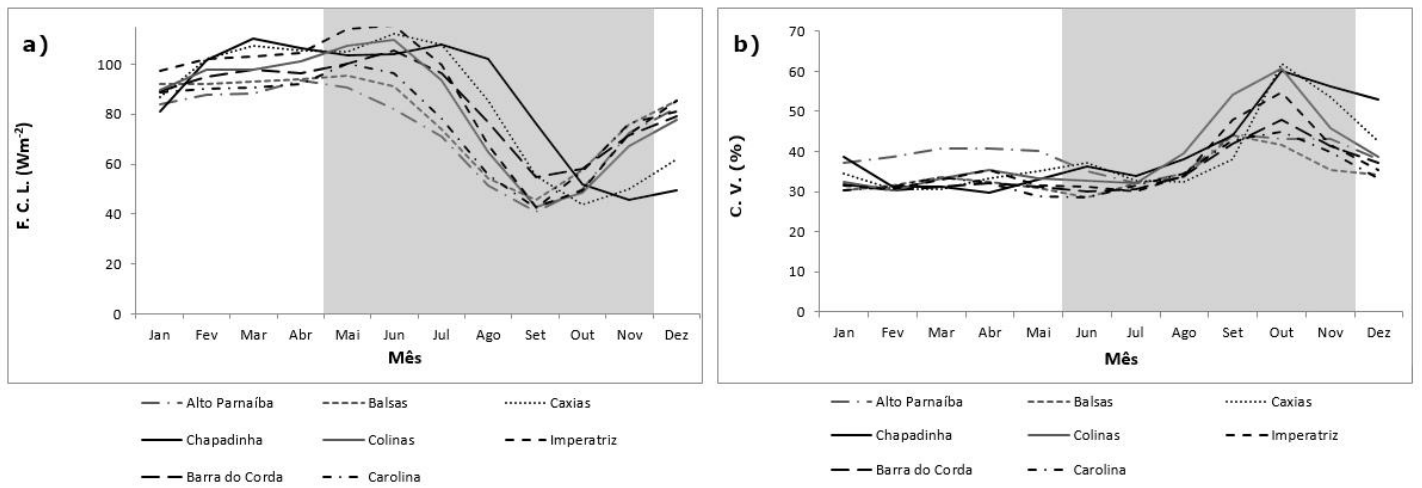

Figura 12 - a) Média mensal do período de 2000 a 2014 do fluxo de calor latente (F. C. L.) nas localidades do bioma Cerrado no estado do Maranhão. b) Coeficiente de variação (C. V.) mensal do período de 2000 a 2014 do fluxo de calor latente nas localidades do bioma Cerrado no estado do Maranhão. A região sombreada corresponde ao período seco.

Andrade et al. (2009), na Fazenda Maracaí (Mato Grosso), verificaram maiores valores no período chuvoso e menores no período seco, com $100 \mathrm{~W} / \mathrm{m}^{2}$ e $67 \mathrm{~W} / \mathrm{m}^{2}$, respectivamente. Bem como Christoffersen et al. (2014) e Giambelluca et al. (2009), que verificaram o mesmo comportamento em outras regiões do Cerrado brasileiro.

\subsection{CALOR SENSÍVEL}

No bioma Amazônico os valores mensais de calor sensível demonstraram um comportamento semelhante entre as localidades no período chuvoso e diferenciado no período seco. Os maiores valores foram observados no período seco e os menores no período chuvoso, apresentando o coeficiente de variação entre $38 \%$ a $75 \%$ (Figura 12). O valor máximo foi observado em São Luís (102 $\mathrm{W} / \mathrm{m}^{2}$ em outubro) e o valor mínimo em Bacabal ( $15 \mathrm{~W} / \mathrm{m}^{2}$ em julho). 

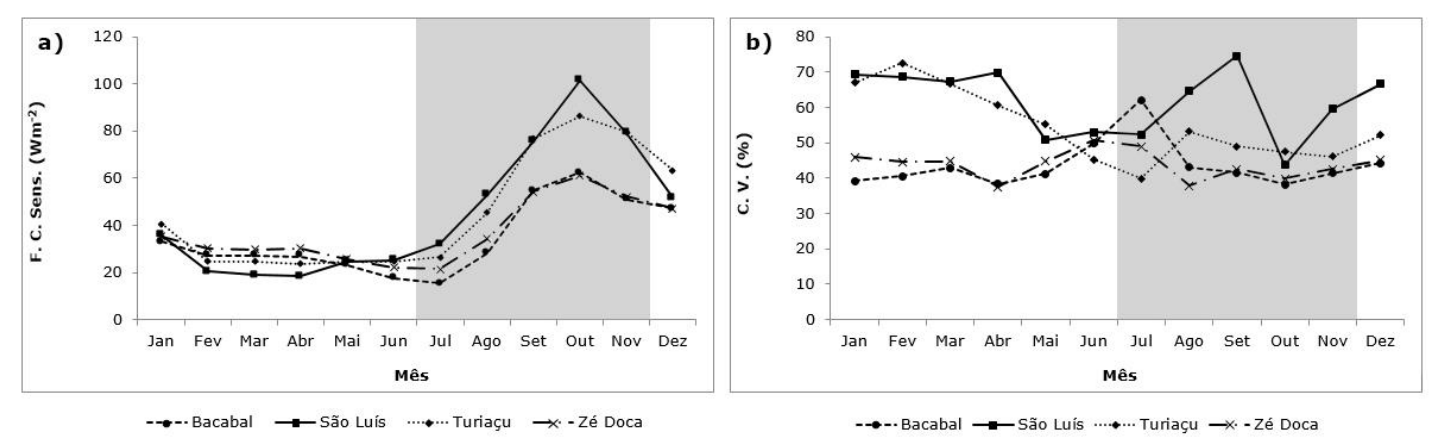

Figura 13 - a) Média mensal do período de 2000 a 2014 do fluxo de calor sensível (F. C. S.) nas localidades do bioma Amazônico no estado do Maranhão. b) Coeficiente de variação (C. V.) mensal do período de 2000 a 2014 do fluxo de calor sensível nas localidades do bioma Amazônico no estado do Maranhão. A região sombreada corresponde ao período seco.

Andrade et al. (2009), na Reserva Biológica do Jaru (Rondônia), localizada no bioma Amazônico, verificaram maiores valores no período seco e menores no período chuvoso, com $24 \mathrm{~W} / \mathrm{m}^{2}$ e $16 \mathrm{~W} / \mathrm{m}^{2}$, respectivamente. Rocha et al. (2004), na Floresta Nacional do Tapajós, também localizada no bioma Amazônico, verificaram valores entre $9,3 \mathrm{~W} / \mathrm{m}^{2}$ e $20,7 \mathrm{~W} / \mathrm{m}^{2}$ no período seco e $10,4 \mathrm{~W} / \mathrm{m}^{2}$ e $16,4 \mathrm{~W} / \mathrm{m}^{2}$ no período chuvoso. De maneira geral, os valores verificados por Andrade et al. (2009) e por Rocha et al. (2004) foram inferiores ao observado no presente estudo, sendo explicado pela latitude da região.

No bioma Cerrado os valores do fluxo de calor sensível apresentaram mínimas variações entre as localidades, com valores superiores no período seco e inferiores no período chuvoso (Figura 13a). O pico no período seco foi verificado em Colinas ( $95 \mathrm{~W} / \mathrm{m}^{2}$ em setembro) e o vale no período chuvoso em Imperatriz ( $6 \mathrm{~W} / \mathrm{m}^{2}$ em maio). O coeficiente de variação apresentou valores entre $30 \%$ e $105 \%$ (Figura 13b).
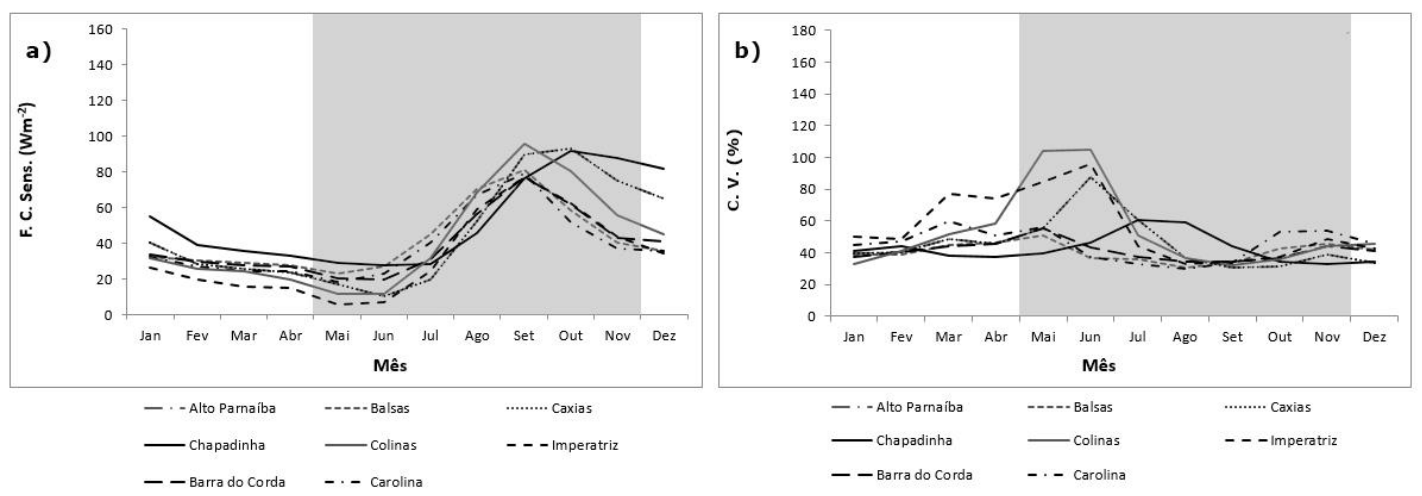

Figura 14 - a) Média mensal do período de 2000 a 2014 do fluxo de calor sensível (F. C. S.) nas localidades do bioma Cerrado no estado do Maranhão. b) Coeficiente de variação (C. V.) mensal do período de 2000 a 2014 do fluxo de calor sensível nas localidades do 
bioma Cerrado no estado do Maranhão. A região sombreada corresponde ao período seco.

Giambelluca et al. (2009), na Reserva Ecológica do IBGE (Brasília), pertencente ao bioma Cerrado, verificaram maiores valores no período seco e menores no período chuvoso, com $89 \mathrm{~W} / \mathrm{m}^{2}$ (agosto) e $51 \mathrm{~W} / \mathrm{m}^{2}$ (janeiro), respectivamente, ambos para um ambiente de cerrado denso.

\subsection{FLUXO DE CALOR NO SOLO}

No bioma Amazônico os valores do fluxo de calor no solo foram superiores no período seco e inferiores no período chuvoso, apresentando o coeficiente de variação entre $-146 \%$ e $160 \%$ (Figura 14 ). O valor máximo foi observado em Turiaçu (3,33 W/m² em setembro) e o valor mínimo em São Luís $(-1,45$ em janeiro). Turiaçu apresentou valores mensais superiores em toda série temporal comparado as demais localidades.
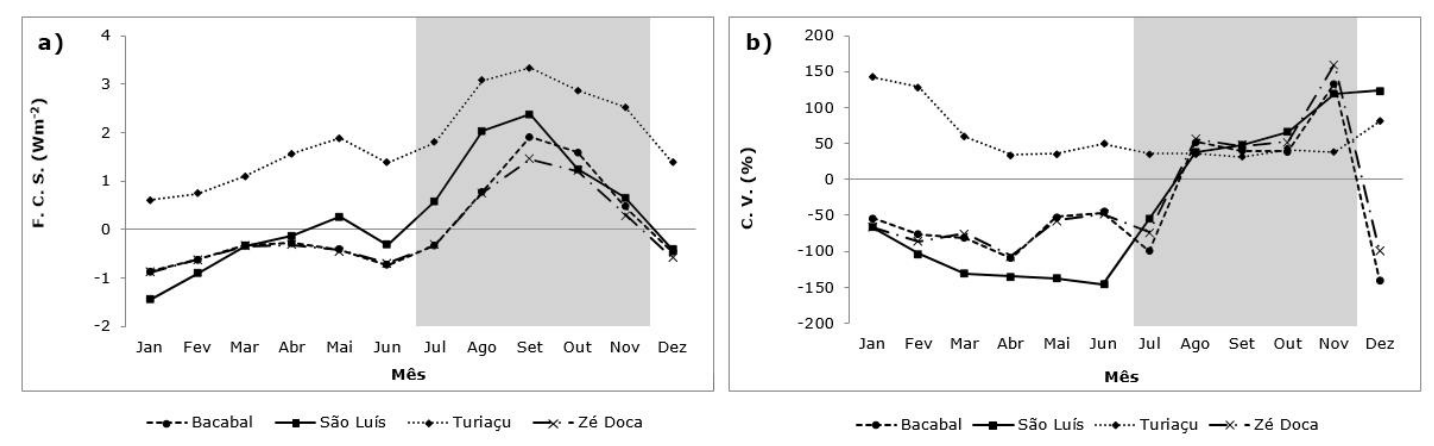

Figura 15 - a) Média mensal do período de 2000 a 2014 do fluxo de calor no solo (F. C. S.) nas localidades do bioma Amazônico no estado do Maranhão. b) Coeficiente de variação (C. V.) mensal do período de 2000 a 2014 do fluxo de calor no solo nas localidades do bioma Amazônico no estado do Maranhão. A região sombreada corresponde ao período seco.

Rocha et al. (2004), na Floresta Nacional do Tapajós, verificaram maiores valores no período seco e menores no período chuvoso. Os mesmos verificaram valores entre $0,1 \mathrm{~W} / \mathrm{m}^{2}$ a $2,8 \mathrm{~W} / \mathrm{m}^{2}$ no período seco e 1,2 a $2,4 \mathrm{~W} / \mathrm{m}^{2}$ no período chuvoso.

No bioma Cerrado os valores mensais não apresentaram um comportamento diferenciado entre as localidades, com maiores valores no período seco e menores no período chuvoso, apresentando o coeficiente de variação entre $174 \%$ e $-514 \%$ (Figura 15 ). O maior valor foi observado em Balsas $\left(2,23 \mathrm{~W} / \mathrm{m}^{2}\right.$ em setembro) e o menor valor em Chapadinha $(-1,10 \mathrm{em}$ janeiro). 

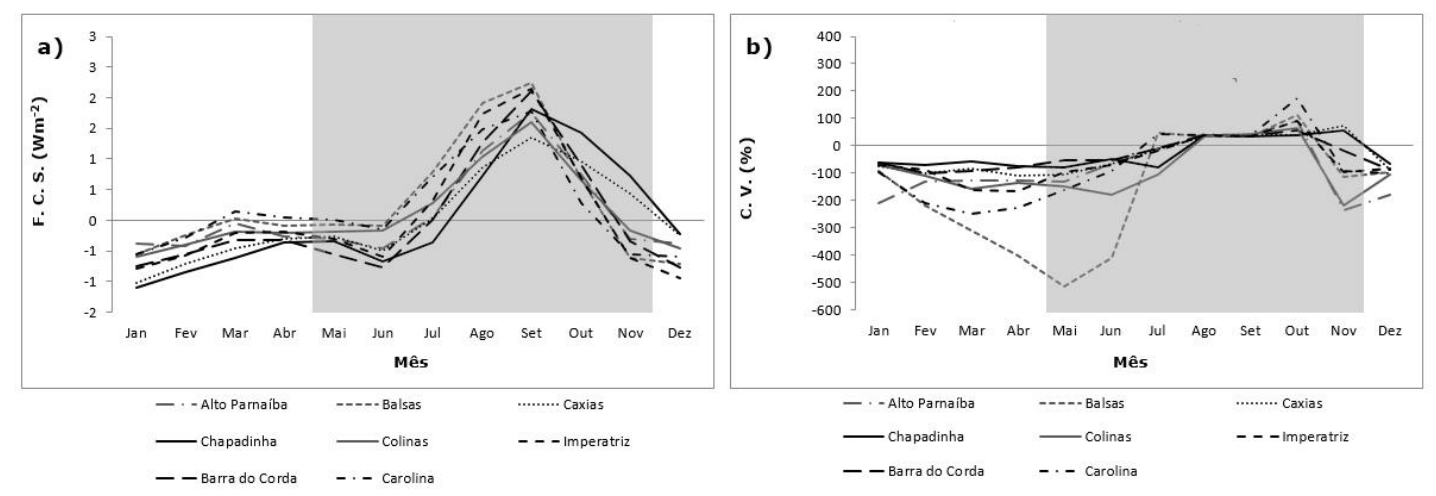

Figura 16 - a) Média mensal do período de 2000 a 2014 do fluxo de calor no solo (F. C. S.) nas localidades do bioma Cerrado no estado do Maranhão. b) Coeficiente de variação (C. V.) mensal do período de 2000 a 2014 do fluxo de calor no solo nas localidades do bioma Cerrado no estado do Maranhão. A região sombreada corresponde ao período seco.

Giambelluca et al. (2009), na Reserva Ecológica do IBGE (Brasília), bioma Cerrado, verificaram maiores valores no período seco e menores no período chuvoso, com 0,7 W/m $\mathrm{m}^{2}$ (outubro) e 0,2 W/m² (janeiro), respectivamente, ambos para um ambiente de cerrado denso.

Dessa forma, os resultados evidenciaram uma grande heterogeneidade das médias do fluxo de calor no solo em ambos os biomas, com maior variação no período seco.

\section{CONCLUSÃO}

Os resultados obtidos neste trabalho mostram que a variabilidade dos componentes do balanço de radiação e calor, da base GLDAS, estão de acordo com observações instrumentais identificadas em estudos nos biomas Amazônico e Cerrado.

As médias mensais da radiação de ondas curtas incidente e do saldo de radiação de ondas curtas, no bioma Amazônico, não evidenciaram um comportamento diferenciado entre os períodos seco e chuvoso, porém no bioma Cerrado apresentam valores superiores no período seco e inferiores no período chuvoso. As médias mensais do fluxo de calor sensível e do fluxo de calor no solo, em ambos os biomas, também apresentam valores superiores no período seco e inferiores no período chuvoso. As médias mensais da radiação de ondas longas incidente, do saldo de radiação de ondas longas e do fluxo de calor latente, em ambos os biomas, apresentam valores superiores no período chuvoso e inferiores no período seco.

De maneira geral, os coeficientes de variação da radiação de ondas curtas incidente, do saldo de radiação de ondas curtas, da radiação de ondas longas incidentes e do saldo de radiação de ondas longas, nos biomas Amazônico e Cerrado, apresentam menores variações. Os coeficientes de variação do fluxo de calor latente no bioma Cerrado e do fluxo de calor sensível no bioma Amazônico também apresentam menores variações. Porém os 
coeficientes de variação do fluxo de calor latente no bioma Amazônico, do fluxo de calor sensível no bioma Cerrado e do fluxo de calor no solo em ambos os biomas apresentam maiores variações.

Portanto, a média mensal da base de dados GLDAS viabiliza estudos de planejamento ambiental em regiões de escassez de dados climáticos, como o estado do Maranhão, servindo de guia para tomadores de decisão, práticas agrícolas, pesquisas climáticas e análises energéticas. Os coeficientes de variação podem ser utilizados como referência a partir da observação dos valores acima ou abaixo da média mensal, principalmente em cenários climáticos futuros.

Trabalhos futuros poderão utilizar dados GLDAS para avaliar o impacto da mudança da cobertura da terra no clima, bem como, avaliar de que forma os elementos do clima contribuem para as mudanças climáticas.

\section{REFERÊNCIAS BIBLIOGRÁFICAS}

AGUTTES, J. P.; GOLDSTEIN, C.; SCHRIVE, J.; RAJU, G.; NARAYANAN, M. S.; DESBOIS, M. Megha - Tropiques: A satellite for studying the water cycle and energy exchanges in the tropics. International Astronautical Congress, Rio de Janeiro, Brasil, v. 51, 2000.

ANDRADE, N. L. R. de; AGUIAR, R. G.; SANCHES, L.; ALVES, E. C. R. de F.; NOGUEIRA, J. de $S$. Partição do saldo de radiação em áreas de Floresta Amazônica e Floresta de Transição Amazônia-Cerrado. Revista Brasileira de Meteorologia, v. 24, n. 3, p. 346-355, 2009.

ARTAXO, P.; GATTI, L. V.; LEAL A. M. C.; LONGO K. M.; FREITAS S. R. de; LARA, L. L.; PAULIQUEVIS, T. M.; PROCÓPIO, A. S.; RIZZO, L. V. Química atmosférica na Amazônia: A floresta e as emissões de queimadas controlando a composição da atmosfera amazônica. Acta Amazônia, Manaus, v. 35, n. 2, 2005.

AWANGE, J. L.; GEBREMICHAEL, M.; FOROOTAN, E.; WAKBULCHO, G.; ANYAH, R.; FERREIRA, V. G.; ALEMAYEHU, T. Characterization of ethiopian mega hydrogeological regimes using GRACE, TRMM and GLDAS datasets. Advances in Water Resources, v. 74, p. 64-78, 2014.

BALDOCCHI, D. D.; MEYERS, T. P. On using eco-physiological, micrometeorological and biogeochemical theory to evaluate carbon dioxide, water vapor and trace gas fluxes over vegetation: a perspective. Agricultural and Forest Meteorology, v.90, n. 1, p. 1-25, 1998.

BASTIAANSSEN, W. G. M. Remote Sensing in Water Resources Management: The State of the Art. International Water Management Institute. Colombo, Sri Lanka, p. 118, 1998.

BARRAZA, V. et al. Estimation of latent heat flux over savannah vegetation across the North Australian Tropical Transect from multiple sensors and global meteorological data. Agricultural and Forest Meteorology, v. 232, p. 689-703, 2017. 
BORGES, C. J. R.; AZEVEDO, P. V. de; SILVA, V. de P. R. da; CAMPOS, J. H. B. da C.; MOURA, M. S. B. de; SOARES, J. M.; SILVA, B. B. Influência do calor armazenado no sistema solo-planta no balanço de energia em pomar de mangueiras. Revista Brasileira de Engenharia Agrícola e Ambiental. Campina Grande-PB, Brazil, v. 12, n. 4, p. 393-399, 2008.

CHRISTOFFERSEN, B. O. et al. Mechanisms of water supply and vegetation demand govern the seasonality and magnitude of evapotranspiration in Amazonia and Cerrado. Agricultural and Forest meteorology, v. 191, p. 33-50, 2014.

COCKSHULL, K. E.; GRAVES, C. J.; CAVE, C. R. J. The influence of shading on yield of glasshouse tomatoes. Journal of Horticultural Science and Biotechnology, v. 67, n. 1, p. 11-24, 1992.

CULF. In: JHC. GASH, J. H. C; NOBRE, C. N.; ROBERTS, J. M; VICTORIA, R. M, Editors, Amazonian Deforestation and Climate, Wiley, Nedlands, W.A.1996.

GIAMBELLUCA, T. W.; SCHOLZ, F. G.; BUCCI, S. J.; MEINZER, F. C.; GOLDSTEIN, G.; HOFFMANN, W. A.; ... \& BUCHERT, M. P. Evapotranspiration and energy balance of Brazilian savannas with contrasting tree density. Agricultural and Forest Meteorology, v. 149(8), p. 1365-1376, 2009.

HASLER, N.; AVISSAR, R. What controls evapotranspiration in the Amazon basin. Journal of Hydrometeorology, v. 8, n. 3, p. 380-395, 2007.

HUTLEY, L. B.; O'GRADY, A. P.; EAMUS, D. Monsoonal influences on evapotranspiration of savanna vegetation of northern Australia. Oecologia, v. 126, p. 434-443, 2001.

IBGE. Estados. Instituto Brasileiro de Geografia e Estatística. 2015. Disponível em: <http://www.ibge.gov.br/estadosat/perfil.php?lang $=\&$ sigla $=$ ma $>$ Acesso em 14 fev. 2017.

IBGE. Estados. Instituto Brasileiro de Geografia e Estatística. 2010. Disponível em: <http://www.ibge.gov.br/estadosat/perfil.php?lang=\&sigla =ma > Acesso em 14 fev. 2017.

JARVIS, P. G.; MASSHEDER, J. M.; HALE, S. E.; MONCRIEFF, J. B.; RAYMENT, M.; SCOTT, S. L. Seasonal variation of carbon dioxide, water vapor, and energy exchanges of a boreal black spruce forest. Journal of Geophysical Research: Atmospheres, v. 102, p. 28953-28966, 1997.

LEITÃO, M. Balanço de Radiação em três ecossistemas da Floresta Amazônica: campina, campinarana e mata densa. São José dos Campos. 135p. INPE 5587TDI/549). (Dissertação)- Pós Graduação em Meteorologia, Instituto Nacional de Pesquisas Espaciais, São José dos Campos, 1994.

MARANHÃO (Estado). Atlas do Maranhão. Gerência de Planejamento e Desenvolvimento Econômico/Laboratório de Geoprocessamento - UEMA. Maranhão, São Luís, v. 2, p. 44, 2002.

MIRANDA, A.C.; MIRANDA, H.S.; LLOYD, J.; GRACE, J.; FRANCEY, R. J.; MCINTYRE, J. A.; MEIR, P.; RIGGAN, P.; LOCKWOOD, R.; BRASS, J. Fluxes of carbon, water and energy over Brazilian cerrado: an analysis using eddy covariance and stable isotopes. Plant, Cell and Environment, v. 20, p. 315-328, 1997. 
MONTES, M. L. Zoneamento Geoambiental do Estado do Maranhão. Ministério de Planejamento, Orçamento e Coordenação da Fundação Instituto Brasileiro de Geografia e Estatística - IBGE. Bahia, Salvador, 1997.

MUNIZ, F. H. A vegetação da região de transição entre a Amazônia e o Nordeste: diversidade e estrutura. Programa de Pós-graduação em Agroecologia/UEMA. 2ed, Maranhão, São Luís, v. 1, p. 53-69. 2006.

PAIVA, C. M. Estimativa do Balanço de Energia e da Temperatura da Superfície Via Satélite NOAA-AVHRR. Tese de Doutorado em Meteorologia por Satélite Universidade Federal do Rio de Janeiro. Rio de Janeiro, RJ - Brasil, p. 218, 2005.

PEREIRA, A. B.; VRISMAN, A. L.; GALVANI E. Estimativa da radiação solar global diária em função do potencial de energia solar na superfície do solo. ScientiaAgricola, v. 59, n. 2, p. 211-216, 2002.

QUEIROZ, A. T. de; RILDO, A. C. Caracterização e variabilidade climática em séries de temperatura, umidade relativa do ar e precipitação em Ituiutaba - MG. Caminhos de Geografia. Uberlândia, v. 13, n. 43, p. 346-357, 2012.

QUERINO, C. A. S.; MOURA, M. A. L.; LYRA, R. F. F.; MARIANO, G. L. Avaliação e comparação de radiação solar global e albedo com ângulo zenital na região amazônica. Revista Brasileira de Meteorologia, v. 21(3a), p. 42-49, 2006.

ROCHA, H. R. da; GOULDEN, M. L.; MILLER, S. D.; MENTON, M. C.; PINTO, L. D.; FREITAS, H. C. de. Seasonality of water and heat fluxes over a tropical forest in eastern Amazonia. Ecological applications, v. 14, p. 22-32, 2004.

RODELL, $M$. et al. The global land data assimilation system. Bulletin of the American Meteorological Society, v. 85, n. 3, p. 381-394, 2004.

ROERINK, G. J.; SU Z.; MENENTI, M. A. Simple Remote Sensing Algorithm to Estimate the Surface Energy Balance. Physical Chem. Earth, v. 25, n. 2, p. 147 - 157, 2000.

SANTOS, A. J. B.; SILVA, G. T. D. A.; MIRANDA, H. S.; MIRANDA, A. C. ; LLOYD, J. Effects of fire on surface carbon, energy and water vapour fluxes over campo sugo savanna in central Brazil. Functional Ecology, v. 17, p. 711-719, 2003.

SILVA, F. B. Modelagem da produtividade primária bruta na Amazônia. Tese de Doutorado em Sensoriamento Remoto - Instituto Nacional de Pesquisas Espaciais. São José dos Campos, São Paulo, 2013.

SILVA, F. B. et al. Evidências de mudanças climáticas na região de transição Amazônia-Cerrado no estado do Maranhão. Revista Brasileira de Meteorologia, v. 31, n. 3, p. 330-336, 2016.

SOUZA, J.; COHEN, J.; COSTA, A.; LOPES, Z. Soil temperature and moisture variability, beneath forest, pasture and mangrove areas. In Eastern Amazonia. II Conferência Científica Internacional do Experimento LBA. Manaus-AM, 2002.

SOUZA FILHO, J. D. C.; RIBEIRO, A.; COSTA, M. H.; COHEN, J. C. P.; ROCHA, E. J. P. Variação sazonal do balanço de radiação em uma floresta tropical no nordeste da Amazônia. Revista Brasileira de Meteorologia, v. 21, n. 3b, p. 318330, 2006. 
VOURLITIS, George L. et al. Energy balance and canopy conductance of a tropical semi-deciduous forest of the southern Amazon Basin. Water Resources Research, v. 44, n. 3, 2008.

WALTHER, G. R.; POST, E.; CONVERY, P.; MENZEL, A. Ecological responses to recent climate change. Nature, v. 416, p. 389-395, 2002. 